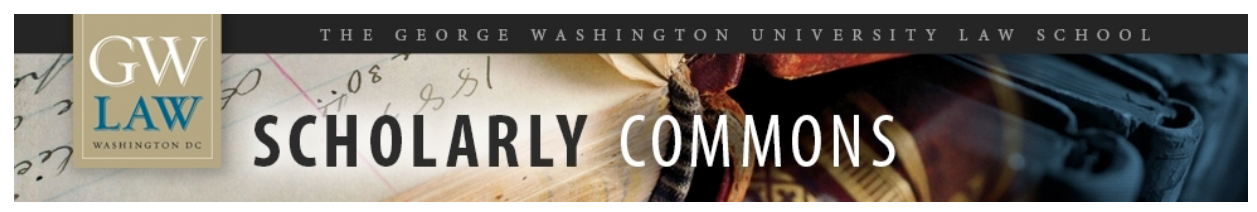

GW Law Faculty Publications \& Other Works

Faculty Scholarship

2011

\title{
Masculinities and Child Soldiers in Post-Conflict Societies
}

Naomi R. Cahn

George Washington University Law School, ncahn@law.gwu.edu

Dina Francesca Haynes

Fionnuala D. Ni Aolain

Follow this and additional works at: https://scholarship.law.gwu.edu/faculty_publications

Part of the Law Commons

\section{Recommended Citation}

Naomi Cahn, Masculinities and Child Soldiers in Post-Conflict Societies in MASCULINITIES AND LAW: A MULTIDIMENSIONAL APPROACH (Frank Cooper, Ann McGinley, eds., NYU Press, 2011).

This Book Part is brought to you for free and open access by the Faculty Scholarship at Scholarly Commons. It has been accepted for inclusion in GW Law Faculty Publications \& Other Works by an authorized administrator of Scholarly Commons. For more information, please contact spagel@law.gwu.edu. 
Masculinities and Child Soldiers in Post-Conflict Societies

Fionnuala Ní Aoláin, Naomi Cahn, and Dina Haynes

A fairly substantial amount of literature has been generated over the years regarding the forms of masculinity that emerge in times of armed conflict and war (Goldstein 2001; YuvalDavis 1997). This war-focused literature (which links to, among other things, masculinities studies) has drawn from broader theoretical research identifying an organic link between patriarchy, its contemporary manifestations, and various forms of masculinity as they arise within societies and institutions (Connell 2005; Cohen 2009). It builds on, and extends, the more general scholarship that has deepened our understanding of how masculinities are constructed and differentiated (Chodorow 1994; Connell 1987; Dowd, Levit, and McGinley this volume). While the war literature has made significant conceptual and practical use of the term "masculinity" to explore the impacts and effects of conflict, the concept has been less applied and understood to be relevant in post-conflict and transitional contexts, as societies attempt to move away from conflict. We argue that masculinities theory and its practical implications have been significantly under-utilized as a lens to explore and address the ending of hostilities in violent societies (Connell 2005; Kimmel 2005). This Chapter suggests that with some notable exceptions (Theidon 2009), little attention has been paid to masculinities in conflict-ending contexts. Moreover, throughout the negotiation, reconstruction, mediation, and intervention phases, masculinities studies concepts and theorization have been underutilized and under-applied to the range of post-conflict actions and actors. Bringing masculinities into view in post-conflict settings provides a more thorough means and framework for addressing the complex social and political problems faced by societies seeking to move beyond violence. 
Conflicted and post-conflict societies are an ongoing source of international attention and resources. They are sites of extremity and instability in many regions. Their successful transition from violent to peaceful (and typically from illiberal to more liberal forms of governance) has regional and global implications. Understanding the relationship between communal violence, masculinities, and the intergenerational transmission of deeply destructive social behaviors should be fully integrated into social, political, and economic problem solving. Masculinities studies, then, has much to offer the seemingly intractable political, legal, and social problems that accompany violent hostilities.

This Chapter proceeds as follows. Part I sets out the application of relevant theoretical concepts to the conflict, post-conflict, and transitional terrains. We introduce and explore the key concepts of hegemonic and hyper-masculinity, drawing on a feminist approach to masculinities studies. Part II addresses the complex interplay between victim and perpetrator status, and the difficulties for men in acknowledging their own experiences as victimhood. This section offers a more nuanced understanding of male victimhood in violent societies, and the silences and barriers that operate to deny the vulnerability of men. It begins the exploration, continued in the next section, of the effects of conflict on children, including the intergenerational impact. Part III focuses on child soldiers, one of the most visible and vulnerable populations affected by the hyper-masculinity of war. It applies theories and constructs from masculinities studies to address the resolution of social, political, and accountability issues that arise from the deployment of child soldiers in armed conflicts. We recognize that the application of masculinities theories does not offer a "one size fits all" solution to every conflict, nor will the issues experienced by and challenging child soldiers be identical across all contexts of violent hostilities. Rather, the knowledge base is one that can widen and deepen our perspectives on child soldiers and allow for creative interventions to support the resolution of a highly complex set of social and cultural issues. 


\section{Hegemonic and Hyper-masculinities in Conflict Settings}

Masculinities theories and feminist analysis have not always worked in tandem, and only relatively recently have feminist scholars sought to address what masculinity studies has to offer feminist theorizing (Dowd 2010). Using the gender lens drawn from various strands of feminist theorizing (Ní Aoláin, Haynes, and Cahn 2011), we start by asking the "man” question, interrogating where and how men are situated in relation to the creation, perpetration, and institutionalization of violence (Dowd 2010). In particular, how are men situated in relation to systematic and structural forms of violence aimed at the destruction of groups, communities, infrastructure, and social functioning? In what ways does hegemonic masculinity work, and how do masculinities operate to benefit even those men who are at the margins of masculinity norms and practice? Are there particular aspects of hegemonic and hyper-masculinity that operate in armed conflicts (and their aftermath) that can be differentiated from the forms that appear in comparatively peaceful societies?

We start with the notion of hegemonic masculinity that defines a dominant conception of masculinity as “a man in power, a man with power and a man of power” (Kimmel 2009, 61). Understanding hegemonic masculinity is critical to seeing how the manifestation of manhood in multiple societal settings reinforces the power that some men maintain over women and other men. Hegemonic masculinity affirms such characteristics as “heteronormativity, aggression, activity, sports-obsession, competitiveness, stoicism, and not being female or feminine” (Cohen 2009, 144). Hegemonic masculinity is “as much about [men’s] relation to other men as it is about relation to women” (Dowd 2008, 233). Somewhat ironically, even within the hierarchies of masculinity, subordinated masculinities can benefit from the social construction of male privilege and values. That hegemonic masculinities are embedded in multiple sites of social interface underscores their pervasive influence upon 
social interaction between groups of men, within familial and communal settings for men, and between men and women.

Much of the theoretical work exploring masculinities has been undertaken in western liberal societies. Many of the assumptions built into theorizing men and male experiences are grounded in empirical and anecdotal experiences of men living in western democracies, who have at least theoretical access to a range of social and other opportunities and where there is hypothetically greater capacity for social mobility. Important to our comparative application, Western societies are generally not perceived as having abnormal or excessive levels of violence, at least not as measured by conflict violence scales. Accordingly, in societies with fewer opportunities for men and in which access to social and economic capital is highly variable across social and cultural groups, the crossover and application of masculinities theorizing requires some adjustment. In societies where social choice and mobility is far more restricted and cultural assumptions about gender roles and expectations are far more deeply entrenched and immovable, conceptions of manhood may be more rigid and cultural differences as to familial role and communal roles may need to be integrated more fully into the analysis.

\section{A. Conflict and Hyper-masculinity}

While some generalizations are accurate concerning the role of masculinities in violent conflicts, the societal context matters. In studying these contexts, masculinity cannot be essentialized based on a view that all men are violent and all women are victims (Abrams 2010; Ní Aoláin, Haynes, and Cahn 2011). We must also guard against the possibility that apparent challenges to masculinities practices can "[entrench] hegemonic masculinity in other ways by perpetuating gender stereotypes positioning all men as prone to violence and all women as vulnerable to victimization and displacing the men and women that operate outside these binary constructs” (Abrams 2010, 703). 
Of particular interest to our analysis is the lens of hyper-masculinity, "a masculinity in which the strictures against femininity and homosexuality are especially intense and in which physical strength and aggressiveness are paramount” (Harris 2000, 793). Other kinds of masculinities coexist with hyper-masculinity, but in situations of conflict, hyper-masculinity plays an enlarged and elevated role. Its social traction is intensified when violence is endemic, and other strictures (social, economic, legal) are slackened; and the unloosening of these patterns and hierarchies is particularly fraught in the post-conflict process.

An important reference point across both conflicted and non-conflicted states is the correlation (and in some societies the codependency) of hegemonic and hyper-masculinity with the role of the military. In the context of contemporary armed conflicts, the term military includes state military forces but also insurgent groups, secessionist movements, paramilitary organizations, and other non-state military entities. It may also include international military in the form of peacekeepers and hybrid groupings comprised of international and domestic military forces. The military is closely tied to manhood, and, indeed, militaristic actions are supported by an ideology of male toughness (Goldstein 2001; Theidon 2007). Hegemonic masculinity pervades and defines sex roles in the military (Abrams 2010). Men dominate most national and international militaries. A swathe of research evidences that the military trains its members to see desirable masculinity as intertwined with violence in an effort to create the appropriate mindset of soldiers who are prepared to fight aggressively to defend their countries (Baaz and Stern 2009). The military is designed around male images that "tacitly exclude others who contradict their image of the combat, masculine warrior" $(\mathrm{O}$ ' Dunivin 1997, 16-17). The military is also clearly identified with institutionalized and highly gendered practices including, until recently, homophobia and the exclusion of women from combat roles in many countries (Dunivin 1977). The opposition of military hierarchies in many states to the inclusion of openly gay and lesbian personnel is deeply implicated in the 
maintenance of ostensibly heterosexual and singularly masculine cultures in the military (Kaplan 2003). By the time conflict ends, men who have acted militarily and the (generally) male political elite are deeply enmeshed in this cultural vision of manhood. As former combatants in Colombia explained to anthropologist Kimberly Theidon, for example, joining a paramilitary group allowed the men "to 'feel like a big man in the streets of their barrios,' to 'go out with the prettiest young women,' and to 'dress well,' privileges they insist would not have been possible if they weren’t carrying a gun” $(2007,76)$. The prevalence of this kind of masculinity poses complex issues for undoing violence, for mainstreaming gender equality, and for remaking societies that have been fractured and deeply divided.

Post-conflict societies present a unique and under-analyzed site of examination for masculinities. One of the main reasons for this lack of attention is the presumption that the post-conflict context is equated to peace and that the absence of war makes moot any analysis of masculinity, which is presumed to have been "tamed" by the end of violent contestation (Ní Aoláin, Haynes, and Cahn 2011). This presumption is misguided. It fails to account for the many ways that the hyper-masculinization inherent in hostilities continues to affect societies and underestimates the ways in which pre-existing conceptions of masculinity influence the transition process. For example, women continue to experience intimate violence in post-conflict societies, and the locales of violence may shift in post-conflict societies such that many violent societies experience significant increases in ordinary criminality as hostilities technically end (Hamber 1998). Moreover, the transition process may attempt to reconstruct the patriarchal legal, social, and cultural institutions that existed pre-conflict (Ní Aoláin, Haynes, and Cahn 2011). Thus, while armed conflict between combatants may end as a result of a peace treaty or ceasefire agreement, violence may remain a persistent feature of the social and cultural landscape of post-conflict societies. 
Understanding what happens post conflict to men (and women) who have been violent in situations of armed conflict is essential to tracking these patterns of shift and movement in the sites of violence. Masculinities may also be critical to understanding why armed conflict reignites in many theoretically "post”-conflict societies, and why the long-term traction of peace agreements is limited (Collier 2009). Consequently, close attention to the forms and impact of masculinities in the post-conflict milieu is critical for the success of the transition itself.

The post-conflict environment, like the conflict environment, is also "vividly about male power systems, struggles and identity formation” (Handrahan 2004, 433). There may be an enormous flux in the male post-conflict fraternity both on an individual and communal level. Moreover, international organizations and institutions, typically headed by male elites, are arriving to reconfigure the transitioning society. So, men who were in power are losing power, other men (domestic and international) are taking their place, and internationals (generally culturally and politically differentiated other males) are coming into a society to fill a vacuum. In this flux of come and go, the gains and losses made by men as individuals or men as representatives of social, cultural, or political groups are critical to the long-term success of the transition from war to peace. Of particular relevance is what happens to the men who symbolically or practically "lose” the war. In assessing this loss, the tools of masculinities scholarship can evaluate the consequences of these perceived failures on men's own professed self-worth, when value is based upon traits of strength, success, and control in “making” and respecting the man. The ongoing pressure to conform to the idealized version of manhood in a society where social and economic choices are few may be organically linked to the repeat player problem in internal conflicts. This challenge is generally engaged by having the same actors cyclically engaged in violence, then cyclically disarmed and demobilized, only to return to armed combat again. Perpetual cycles of violent conflict 
intractability may be related to the cultural vision of manhood that props up ongoing reversion to violence, to "securing the win,” as much as to other economic and political factors.

One enduring question that emerges from the conflict and masculinities literature iswhy do men engage in violence? To begin with, violence, as an aspect of masculinity, is deeply linked to the assertion of social status and the value of self in particular contexts. Violence may literally "make the man" in many societies, and not infrequently the site of the violence is the woman's body. Recent empirical studies investigating why men rape expose the fact that soldiers "explicitly link their rationale for rape with their inabilities (or 'failures') to inhabit certain idealized notions of heterosexual manhood” (Baaz and Stern 2009, 497). Indeed, soldiers pointed to the discord between their embodied experiences and their expectations of themselves as soldiers (men) in the armed forces as a site of frustration, negotiation, and an underlying incitement to sexual violence (ibid.).

While the causes of violence and conflict in a range of societies are complex (Scherrer 2002), a number of cluster causalities are useful to identify. Violence is typically associated with the following: first, economic and social insecurity; second, a lack of legal and political status particularly associated with group or ethnic identity; and third, the lack of opportunity for meaningful self-determination (whether external or internal) within the state. In multiple contexts, engaging in violence is a rational choice for men when few other opportunities may be provided to gain economic security (albeit that participation in violence provides a highly tenuous economic existence or longevity), social status and value within their communities, and security (again albeit tenuous and fragile) for their families and communities.

The existence of such deeply rooted links between the constructions of the masculine self and the social acceptance of "manhood" means that uncoupling the political contexts which bring about the formal end to hostilities from broader social and cultural contexts that 
produce certain kinds of masculine behaviors and values is complex. The end of violence is not a superficial engagement, but may require deep and difficult entanglement with the masculine construction of self in many societies. In post-conflict societies, where there is no functioning governance or economic structure, such conundrums are compounded by the lack of other opportunities available to men to assert positive masculinities. Such positive masculinities include caretaking and support roles, roles that evidence nurturing capacity, and engaging in a broad range of social and economic activities that in highly gender stratified societies would be gendered female.

\section{B. Masculinities and the Ending of Conflicts}

This question of violence and its ending is central to the post-conflict experience because the cessation of public violence between (generally) male combatants is usually the litmus test for evaluating the success of the transition from war to peace. We take issue with the presumption that the end of public violence and the measurement of security based on the safety of male combatants should constitute an adequate calculation of peace in any society. Instead, achieving peace requires accounting for, and directly addressing, the causes of violence, a process that requires engaging inter alia with hyper-masculinity. Of course, issues of causality are extremely complex, dependent on variations in social and cultural contexts. Nonetheless, post-conflict literature has begun to explore the strong overlap between the causes of violence and the emergence of certain forms of masculinity in conflicted societies. If we fail to address the causalities discussed above within a framework that integrates gender and masculinities, we may also fail to address the ongoing realities of how masculinities closely interconnect with post-conflict social, political, and economic outcomes.

In addition to recognizing the forms and patterns of masculinities emerging in conflict and post-conflict situations we must also acknowledge the specific masculinities associated with international intervention and the cadre of male elites who come into conflict endings 
exercising multiple roles and functions. Beyond a more nuanced recognition of these international masculinities, we also want to address the complex set of role assumptions for men and women in post-conflict societies. This requires asking the fundamental question of what does it mean “to be a man” in a violent society, when violence begets status and economic capacity? What happens to such masculinities when societies transition from violence and move towards democratic or more liberal forms of political engagement? Which men lose and gain in such contexts? What happens to women when men experience this role instability? As both Brandon Hamber and Amy Maguire have explored in post-apartheid South Africa and transitionary Lebanon, respectively women often bear the brunt of the flux in masculine roles (Hamber 2006; Maguire 2009).

Formal (equality) gains made by women in many post-conflict legislative and constitutional enactments conjoin with the political displacement of power for many men from the traditional routes provided during armed conflict to create a complex social and legal terrain. It is upon this territory that women’s gains and their intersection with masculinities in flux are played out. Formal gains for women may, in fact, be nullified or significantly constrained by the reality of social and community context, in which the accommodation of men's deeply entrenched social status may outweigh the enforcement of formal legal norms in practice. Moreover, the social realities that women confront in highly patriarchal societies are propped up and perpetuated by masculinities in action-limiting the reach of law in subtle and crosscutting ways.

It is also vital to contextualize the reality of economic fragility faced in post-conflict zones around the world. Countries emerging from conflict are some of the poorest on the planet. Consider that, as of 2008, Somalia’s Gross Domestic Product (GDP) per capita was \$600; Rwanda’s GDP per capita was \$1000; Burundi’s GDP per capita was \$400; and Colombia’s GDP per capita was $\$ 8800$ (Central Intelligence Agency 2009). They have the 
highest number of refugee populations (who are predominantly female with child dependents) and internally displaced persons. For example, as of January 2009, Rwanda hosted 55,062 refugees; Somalia hosted 1842 refugees and 1,277,200 internally displaced persons; Burundi had 21,093 refugees and 100,000 internally displaced persons; and Colombia had 170 refugees and 3,000,000 internally displaced persons (UNHCR 2009). In this context, when one domain of status and economic subsistence is closed off (by the end of violent armed conflict) such societies struggle to replace the dysfunctional economy of war with a functional liberal economy of provision. The tools that for some men provided a means of survival in war are unreliable and may no longer be needed. Men and young boys who are under- or uneducated are at a considerable and material disadvantage in such settings. In this space of economic struggle, Gary Barker and Christine Ricardo illustrate the rise in the parallel economics of criminality and "normal” violence, which allow certain forms of masculinity to endure and provide both status and material gains (2005). They note the particular difficulties of confronting violent masculinities in social settings that have operated to seal off men spatially from women and children. This is further compounded in societies that have deeply stratified gender roles, leaving little room for the expression of positive masculinities in either the public or private sphere. The effects of such stratification are also intensified when one accounts for intergenerational transmission of violent norms, as well as in societies where age stratification is intense, creating intense competition for economic and sexual resources as well as opportunities (ibid., 12).

\section{Male Victimization in Conflict and Post-Conflict Settings}

Rather than essentialize men's roles during conflict as characterized by hyper-masculinity, it is vital to acknowledge that men and boys may also have been victimized throughout violent conflicts — possibly by abduction, possibly by sexual violence, almost certainly by the violent ritualization that frequently accompanies male initiation into predominantly male military 
fraternities. A particular taboo is evident in recording or acknowledging the experiences of sexual violence by male combatants and male civilian bystanders. ${ }^{\mathrm{i}}$

In this context scholars have increasingly challenged the tendency to frame some sexual crimes, specifically the crime of sexual enslavement, as one that predominantly describes the experiences of women and enslavement simple (without a gender based dimension) as only affecting men and boys (Oosterveld 2010). In such a limited gender analysis "men are 'just' slaves whilst their female counterparts are 'just’ raped” (ibid, 4) The approach fails to account for the ways in which in the context of enslavement of boys, sexual vulnerability is ever present and sexual and reproductive ownership limits the ways in which boys' sexual development and maturing is controlled and exploited (ibid.; Bridgewater 2005). Essentialist constructions are clearly overly simplistic and fail to account for the totality of violence and harm experienced by men, women, boys and girls in conflict contexts.

As Chris Dolan has noted in the context of documenting the rape of men in Northern Uganda, male rape is little discussed (Neumann 2009). Male rape practices in this setting were viewed as an affront to male identity and to the society as a whole and discounted or under-acknowledged in social and political settings. Violent sexual attacks on men were viewed as an attack on the integrity of the community (more so even than the rape of women), but in practice were downplayed in terms of their actual occurrence and little support or social sympathy was forthcoming for victims. ${ }^{\text {ii }}$

The taboo on addressing male victimization trickles down from the dominance of hegemonic masculinity in which to be a victim is to be relegated to a domesticated and vulnerable status. To be the male victim of sexual violence is to be defined in womanly terms as “soft and weak and incompetent” (MacKinnon 1982, 530). There is some nascent literature that suggests a link between sexual violence of men by men and deeply rooted practices of feminization (UN OCHA 2008). In this telling, sexual violence experienced by men is a 
direct playing out of wider social (and violent) practices that are generally directed toward women. For many men who experience rape, the result is to undermine their own masculinity in fundamental ways and put in doubt their sexual identity. Based on homophobia, many societies stigmatize the existence of male/male rape because it involves sexual activity between men and is viewed as indicative of homosexuality regardless of the coercion involved (Sivakumaran 2005). Sexual violence experienced by men is, we know, significantly underreported, although empirical proof other than anecdotal evidence is difficult to establish. The statistics of the Peruvian Truth and Reconciliation Commission (TRC) suggest that men may underreport (even as the statistics illustrate that women are the most prevalent victims of sexual violence). Of the 538 cases of sexual violence reported to the TRC, 527 correspond to women and only eleven were attributed to male victims (Duggan, Bailey, and Guillerot 2008). As is generally noted in the context of sexual violence experienced by women, underreporting is rife, and we do not have a deep understanding of the form, dynamics, and scale of sexual violence that men experience in times of conflict. To do so requires not only seeing how hegemonic and hyper-masculinities underpin the experience of and response to sexual violence as it affects men, women, and the communities they belong to but also how it disempowers men and boys from reporting their experiences.

Male victims may feel caught between the hyper-masculinization of war and their own feelings of vulnerability and stigma (Gettleman 2009). Facilitating acknowledgement of the experiences of violation by men and boys, ensuring reporting, and advancing healing requires developing programs to aid this population. These programs might include specially trained counselors, targeted educational opportunities for boy soldiers, and specific health care measures. Critical in addressing victimization and powerlessness is identifying ways in which victims, male and female, can benefit from forms of social and economic empowerment and 
from the development of positive role models that may help them address and move past their victimization.

\section{Child Soldiers and Intergenerational Transmission of Violent Norms}

Male and female child soldiers present particular challenges to post-conflict reconciliation, and occupy a unique space by inhabiting the boundaries of being both victims and perpetrators simultaneously (Rosen 2009). Regardless of whether they are subjected to socialization into the military as arms-bearing soldiers, as porters, or camp followers, they provide an important subject for masculinities studies. The deployment of child soldiers has been a historical reality in many societies, yet legal developments recognizing the rights of the child through international treaties such as the Convention on the Rights of the Child (CRC) have transformed international and domestic approaches to the use of children as soldiers and to the imposition of any criminal penalties they might face as a result. The first contemporary legal deterrent to using children as combatants came with Protocol I Additional to the Geneva Conventions of 1977, which makes some advances but does not appear to be an outright prohibition on child combatancy. ${ }^{i i i}$ Despite this and the development of international prohibitions on the use of child soldiers, much legal and cultural work remains to be done in setting generally agreed and enforced international standards on the use of persons under 18 in military contexts (Hamilton and Abu El Haj1997). The difficulties are rife as treaty provisions continue to make a distinction between persons under 15 years of age, for whom the prohibitions are generally robust and absolute, and those between 15-18 years old, who can be voluntarily conscripted into military forces. ${ }^{\text {iv }}$ The Optional Protocol to the Convention on the Rights of the Child on the Involvement of Children in Armed Conflicts (Child Soldiers Protocol), which specifically addresses the practice of recruiting and using children as soldiers in armed conflict, bans the use of children under the age of 18 in armed conflicts, although it does permit the voluntary enlistment of 16 and 17 year-olds into armed 
forces (Optional Protocol 2000). It has not, however, been ratified universally (Coalition to Stop the Use of Child Soldiers 2008; UNICEF 2006). Variable criminal standards across multiple jurisdictions on the age at which a child can be held criminally accountable for various crimes also compound the difficulties in setting coherent and generally agreed standards on minor responsibility in law. Estimates vary as to the numbers of children conscripted into state military forces, militias, and other non-state forces, but may be as high as 300,000 in a given year (Drumbl 2011; E. Kaplan 2005), and they can constitute a significant fighting force. The term "child soldiers" is broadly defined to include all children associated with armed groups, and their roles range from combatants to cooks, porters, or camp followers who are used for sexual services (Fujio 2008; Knudsen 2004). The disarmament of child soldiers must resolve thorny legal, moral, and programmatic questions. They include the following: 1) rehabilitating children who have committed serious and systematic human rights violations; 2) ensuring that such children are accepted by their families and communities when the victims of their crimes may have been family or community members; 3) determining whether child soldiers are eligible for asylum under refugee law or must be barred for having persecuted others; 4) addressing the educational and health needs of boy and girl soldiers in societies with scarce resources; 5) finding ways to address the needs and rights of those victimized by child soldiers; and 6) satisfying the demands for criminal accountability in post-conflict societies. In a broader view, the rehabilitation and reintegration of child soldiers is critical to the long-term stability of violent societies as we increasingly understand the intergenerational effects of armed hostilities over the medium and long term. Children who have absorbed and acted out violent norms pose immense challenges to the sustainability of peace and to the broadest possible realization of stability and security. 
One starting point for the application of masculinities studies is the recognition that boys are typically inculcated into cultures whose normative underlay is based on the suppression of emotion. The perceived success of a boy's development (for himself and his family) will be the expression of strength both physical and emotional and the rejection of weakness (judged in similar terms) (Gilmore 1990; Kimmel 2004). The particular weight of responsibility that falls on boys to fulfill masculine and productive expectations from a very early age must be more fully considered in the broader masculinities literature. In societies that experience entrenched and cyclical violence, these pressures are present in concentrated form. When familial and communal structures operate within the dual expectations of the inevitability of violence and of a man's commitment to and support of military action, the pressures for the boy-child and the absorption of hyper-masculinity norms comes early and intensely. Moreover, the range of choices offered to or closed off from the boy-child as combatant in waiting should not be underestimated. Here hegemonic masculinity theory concerning violence as extensions of "normal” masculinity has a particularly deep resonance (Abrams 2010, 714). Moreover such expectations, reinforced by the normality of hostilities, in turn highlight the need for a man to define his masculinity by defending his family, both in the literal and real sense (Gilmore 1990). These messages are clearly carried across generations. In Northern Ireland for example, empirical research examining the murderous targeting of Protestant male heads of household in borderland farming communities (a form of ethnic cleansing) illustrates the enormous social pressures on young men (sons left behind) to protect land and family (and equally become the next subject of paramilitary targeting) (Simpson 2009).

The transmission of intergenerational expectations compounds the entrenchment of stratified gender roles, and can nullify any attempts to advance gender equality and the loosening of gendered expectations around caring and parenting for women. The core point is 
that conflicted societies can mummify highly gendered role expectations for men and for women from early childhood in ways that are quantifiably more intense than in societies not experiencing communal violence. Additionally, in societies experiencing ethnic or religiously driven hostilities, the overlay of "othering" that accompanies the construction of the social and masculine self is profoundly linked to the reproduction of violence through the generations and the valuing and self-identification of the man through violent action. In such contexts, when children engage in violent activities, consent is a highly fraught measurement given the longitudinal socialization to violent norms that may be endemic to upbringing in particular communities.

Child soldiers are a complex group who cannot be essentialized as victims or violent actors (Drumbl 2011). There are numerous factors that influence children to join armed movements voluntarily (or at least without physical coercion), including the poverty in which they live and the lack of opportunities for education or ultimate employment. While not all poor children living in conflict zones become soldiers, it is poverty and conflict that prevent them from attending school or that result in the death of family members who might otherwise provide counsel. One study found that $80 \%$ of child soldier recruits, compared to $20 \%$ of a control group of children who had not become soldiers, observed conflict near their homes (Cahn 2006). Serving with an armed force also can be seen as providing various opportunities, including protection and training (Drumbl 2011; Amnesty International 2010). Adolescents who are working or who are in school and doing well are much less likely sources of recruits than unemployed children with no opportunity for school (Cahn 2006). Joining an armed group provides adolescents with the potential for adventure (ibid.). Children may also join to take revenge against other armed groups who have killed family members. Additionally, both boys and girls may join to escape from oppressive home environments, although girls are far more likely than boys to claim that domestic violence or 
feelings of exploitation were their primary motivation for joining. Once children become associated with armed forces, they undergo efforts to entrench and endorse violence, competitiveness, and destructive capacities; this may become a "proving ground for masculinity” viewed as a "rite of passage, transforming boys into men” (Carreiras 2006, 41). Through participation in conflicts, boys may feel that they have become men, and they may find male role models (Barker and Ricardo 2005).

Child militarization also occurs through coercion, including conscription, abduction, and forced involvement in violent activities, the latter directly aimed at the families and communities they have been taken from. Here, the intended consequences are breaking down familial and social bonds, and destroying the community by the horrific manipulation of its most vulnerable. ${ }^{\mathrm{v}}$ In order to socialize children into the military, for example, their leaders "deliberately brutalise the children from an early stage, forcing them to commit crimes against their will. ... Once on the frontlines, the process of brutalisation continues as children are repeatedly obliged to commit abuses, including murder and rape, against civilians and enemy soldiers” (Amnesty International 2003, 6-7). Equally evident are the unique vulnerabilities of young men and male children who have been conscripted into militias, insurgent groups, or paramilitary forces. As the initial indictments from the International Criminal Court illustrate in relation to the harms visited upon child soldiers, acts of sexual violation were intentional and systematic, clearly intended to break bonds between children and their families/communities of origin and force relationships of dependency and shame into the paramilitary organizations (ICC Warrant of Arrest 2006).

Central to the reassertion of normality in many conflicted societies-as a bridge from war to peace-are DDR (disarmament, demobilization, and reintegration) programs. Heavily endorsed and supported by international intervenors (whether states or international institutions), DDR has been the locus for addressing the neutralization as a military threat of 
the combatant in the post-conflict state. DDR programs and accountability processes have generally failed to account for the emergence of masculinities in violent childhoods, and the "making of the man" in these contexts has long-term effects for the stability and peacefulness of a conflicted society. Demobilization programs that fail to account for the push and pull factors that lead boys into armed conflict cannot hope to effectively contribute to leading a country into sustained peace. The intergenerational transmission of problematic masculinity norms must be more clearly placed in the discourses of transition and peacemaking in order to render post-conflict programs more effective and relevant in securing their stated goal of rendering peace.

Child soldiers may have become adults during the conflict, and will have the same needs as other former combatants for rehabilitation and reintegration. Effective and meaningful DDR would benefit from deconstructing and addressing positively the negative masculinities of militarization processes in which child soldiers have participated. Anyone recruited as a child, however, has also lost educational opportunities and family care and support, issues that must be recognized in any DDR program. Child soldiers who remain children also need services to help them find their families or, where the families cannot be found, make arrangements for foster care (YCare International 2008). Ensuring the integration of children more positively into their families offers some means to redress the complex roles that they must manage in the post-conflict context, helping them manage a transition away from the hyper-masculinizing process they have undergone during the conflict and offering positive alternatives. Educational opportunities provided as part of the DDR must recognize the special needs of children whose schooling and emotional development have been so violently disrupted, resocializing them to effectively dismantle individual and collective wartime behavioral patterns and mentalities. Another important and related move is to extend and broaden the categories of combatants for the purposes of DDR programs, ensuring that 
children who have provided support roles to military or paramilitary forces (as well as those who have been involved in direct hostilities) are included and fully integrated into structured DDR programs. Inclusion in official and appropriately framed DDR programs can, again, help with moving away from a violent mentality instilled by conflict.

Re-socializing former child soldiers requires integrating the information known about the effects of hyper- and other forms of heightened masculinities into the planning and delivery of the DDR programs that are generally constructed and supported by international actors. It means moving the emphasis away from merely handing over guns to neutral arbitrators and instead integrating psychological and reflective counseling into the demilitarization of combatants (Ní Aoláin, Haynes, and Cahn 2011). Ultimately, and far more difficult, it requires providing other economic and social opportunities for boys and men to express masculinities in ways that are not socially and politically destructive.

A key challenge is developing positive gender roles for young men and women who have been egregiously violent, and who have equally been deeply violated. ${ }^{\mathrm{vi}}$ These multiple contexts of male victimization (made more complex by the victims' parallel roles as perpetrators) require melding into the programmatic structure of DDR programs. In particular, DDR programs need to develop special counseling and training programs addressing the harms experienced directly and more broadly, forcing difficult conversations about men’s roles post conflict (United Nations 2006; Bastick 2008). Post-conflict programs must be developed and carried out with an awareness and appreciation for the cause and effect of masculinities during war in order to effectuate post-conflict transitional goals in genuinely transformative ways.

\section{Conclusion}

While violent masculinities are clearly and inexorably evident in conflicted societies, not all conflicts manifest similar kinds of violence, nor are the patterns of violence consistently 
duplicated suggesting that masculinities are not evidenced in the same ways across all conflicts and that limits can be placed on male behavior in war. This insight has relevance for our understanding of how we address the manifestation of masculinities in conflict contexts. Recent empirical work reveals highly relevant variables to the forms and expressions of violence against women in situations of conflict, demonstrating not just the fact of variability but offering significant insight into the kinds of structural and institutional matters that can dampen certain kinds of violent expression in war, and, in particular, sexual violence against women and men (Wood 2006). Understanding violence and how to transition away from it involves identifying the forms of masculinity that emerge in violent conflicts and what limits can be placed on hyper-masculinities or the negative results of hegemonic masculinity in conflict contexts. Factors that limit the experience of harm in war for both men and women include restraining opportunity (namely, ensuring where possible, limitation on access to civilians from combatants), creating or lowering incentives to military personnel for certain kinds of violent action, and creating and enforcing a system of effective sanctions which is highly correlated to the effectiveness of military discipline within any military unit or entity (ibid.). These are all relevant frames to think about in addressing the management of inevitable conflict and to lessen violent impact for men and women.

Post-conflict settings require addressing gender in multiple ways, including through close attention to masculinities as part of the high-priority (and funded) measures to end violence. Programs specifically focused on disarming and reintegrating former combatants need to account for masculinities in their mandates and program deliveries. They need to do so in a thoughtful way that integrates scholarly and interdisciplinary insights squarely into the policy arena.

Masculinities discourses and theory have begun to transform scholarly and practical understandings of the methods and means of warfare, as well as to tease out the causalities of 
war and the means to bring about an end to public communal violence between male combatants. In the context of post-conflict, peacemaking, and transitional discourses, however, attention to masculinities has been much less evident. Our contribution seeks to remedy that gap by bringing the theory and practice of masculinities discourses to bear on these fields, focusing on the particular vulnerability of child soldiers and the victimization of men during conflict. This Chapter has sought to rebut the general presumptions that masculinities disappear at the formal ending of hostilities and during the peacemaking phase of conflict. Rather, masculinities are ever present and deeply problematic to ensuring successful outcomes with a sustainable peace. In particular, we suggest that hypermasculinity maintains its presence in post-conflict societies—and is particularly manifest in the experiences of violence in the private sphere for women and the increases in criminality and "ordinary" violence in transitional societies.

Notwithstanding the cultural, legal, and social variations between countries facing postconflict issues, the core issues around the centrality of gender remain universal. In undertaking this analysis, we are convinced that addressing gender and the differing needs of men and women is not only good policy and practice on its own merits, but that it also meets the first principle of conflicted and post-conflict societies—namely, ensuring that violence ends for all, is not reignited, and that peace is sustainable far into the future.

\footnotetext{
${ }^{\mathrm{i}}$ It is important, then, to acknowledge the men who have recently come forward in the Congo to attest to having been raped by both rebels and Congolese soldiers alike. The American Bar Association, running a sexual violence legal clinic in Goma, states that more than 10 percent of its rape cases in June of 2010 were men who were then cast out by their villages and families, shamed and referred to as "bush wives," the pejorative term used for years to describe women forcibly taken as sex slaves or "wives” of these same soldiers (Gettleman, 2009). The experiences of these men were later discounted.
} 
${ }^{i i}$ In the documentary film Gender against Men in which one individual gives evidence about the experience of being raped 20 years earlier, the testimony itself is highly unusual. In the field where the testimony was taken, the speaker was shouted down in a communal setting, as if the community as a whole did not want to "hear" what had been done.

iii Article 77(2) states that: "The Parties to the conflict shall take all feasible measures in order that children who have not attained the age of fifteen years do not take a direct part in hostilities and, in particular, they shall refrain from recruiting them into their armed forces. In recruiting among those persons who have attained the age of fifteen years but who have not attained the age of eighteen years, the Parties to the conflict shall endeavour to give priority to those who are oldest.”

iv The European Convention on Human Rights allows for voluntary military service from the age of 16 . See also, ICCPR standard and jurisprudence. As regards the Geneva Conventions: there are six articles which specifically concern children under the age if fifteen in the Fourth Geneva Convention of 1949. Of those articles half apply to the general child population of a state party whilst the other half apply to children who fall under the remit of protected persons.

${ }^{v}$ Child Soldiers Global Report found at http://www.childsoldiersglobalreport.org/overview-and-benchmarks, which takes a country by country assessment of the numbers and experiences of child soldiers.

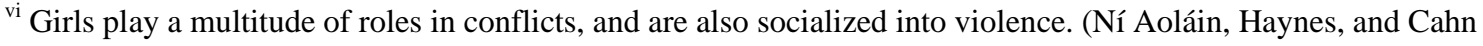
2011). 